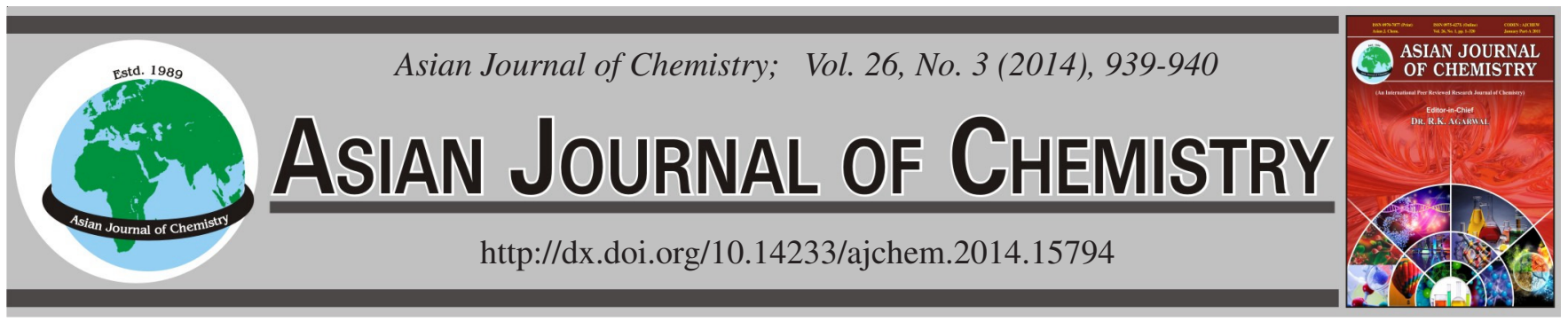

NOTE

\title{
One-Step Synthesis of 2-Thiazolidinone
}

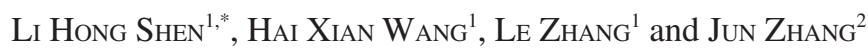

${ }^{1}$ Handan Key Laboratory of Organic Small Molecule Materials, Handan College, Handan 056005, P.R. China

${ }^{2}$ Department of Chemistry, Handan College, Handan 056005, P.R. China

*Corresponding author: E-mail: 1hshen1974@gmail.com; latishen@sohu.com

Received: 18 May 2013;

Accepted: 25 July 2013;

Published online: 30 January 2014;

AJC-14673 An efficient and direct access to thiazolidinone is developed. 2-Thiazolidinone is synthesized by urea and 2-aminoethylmercaptan hydro-
chloride and this one-step process proceeds with good yields, under mild conditions. The structure of the compound was confirmed by IR,
${ }^{1} \mathrm{H}$ NMR, MS and the product purity was $98 \%$ by HPLC.

Keywords: Thiazolidinone, 2-Aminoethanethiol hydrochloride, Urea, Synthesis.

ᄂ - - - - - - - - - - - - - - - -

Thiazolidinone is considered as a biologically important active scaffold that possesses almost all types of biological activities. Thiazolidinone derivatives have been investigated for a range of pharmacologic indications such as antiinflammatory, antimicrobial, antiproliferative, antiviral, anticonvulsant, antifungal and antibacterial activities ${ }^{1-4} \cdot 2$-Thiazolidinone is useful as intermediates for medicines and agricultural pesticides $^{5}$. 2-Thiazolidinone is not only a useful intermediate, but also has good fungicidal activities toward various plant disease fungus. The research and developments for 2-thiazolidinone as key intermediate of Fosthiazate has the great significance for manufacture of Fosthiazate and the plant thelaziasis's prevention ${ }^{6}$.

The conventional methods mentioned in the literature ${ }^{7}$ have various drawbacks of their own. With these in mind, we recently choosed the 2-aminoethanethiol-urea method as industrial synthetic method. The synthetic route of the target compound is outlined in Scheme-I. 2-Aminoethylmercaptan hydrochloride was purchased from Aladdin Reagent Co. Ltd China, with an over $98 \%$ purity.

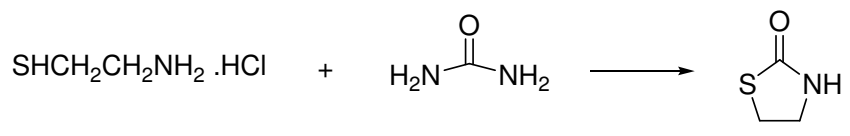

Scheme-I: Synthesis of 2-thiazolidinone

Melting points (uncorrected) were determined on a XT4 MP apparatus (Taike Corp., Beijing, China). IR spectra were recorded by dispersing the compounds in $\mathrm{KBr}$ pellets on a
Schimadzu FT-IR 157 spectrophotometer. ${ }^{1} \mathrm{H}$ NMR spectra were recorded on a Bruker Avance II $400 \mathrm{MHz}$ NMR spectrometer and all the chemical shift values were reported as $\delta$ (ppm). Mass spectra were recorded on a Agilent 6320 ion trap LC/MS instrument

2-Thiazolidinone: 2-Aminoethanethiol hydrochloride $(11.4 \mathrm{~g}, 0.1 \mathrm{~mol})$ and urea $(9 \mathrm{~g}, 0.15 \mathrm{~mol})$ were stirred and heated to $180{ }^{\circ} \mathrm{C}$ and left undergoing reaction. In this while, since ammonia was emanated from the top of the condenser, the reaction was continued with the emanating ammonia kept absorbed in an aqueous hydrochloric acid solution. When the reaction was continued for $3 \mathrm{~h}$ following the rise of the temperature to $180^{\circ} \mathrm{C}$, the emanation of ammonia ceased and the reaction was completed. The cooled reaction mixture was treated with water and the product was obtained by filtration. And extracted with toluene and distilled under a vacuum, white solid 8.8 g, yield $85 \%$, m.p. $49-51{ }^{\circ} \mathrm{C}$, IR $\left(\mathrm{KBr}, v_{\max }, \mathrm{cm}^{-1}\right)$ : $3300,1680,1550,1100 ;{ }^{1} \mathrm{H} \mathrm{NMR}\left(\mathrm{CDCl}_{3}, 300 \mathrm{MHz}, \delta \mathrm{ppm}\right)$ : 3.35-3.41 (m, 2H), 3.57-3.61 (m, 2H), 6.95 (s, 1H, N-H); MS (ESI, m/z): $103.2[\mathrm{M}]^{+}$.

\begin{tabular}{|c|c|c|c|c|c|}
\hline \multicolumn{6}{|c|}{$\begin{array}{c}\text { TABLE-1 } \\
\text { EFFECT OF REACTION TEMPERATURE } \\
\text { ON THE YIELD OF THE PRODUCT }\end{array}$} \\
\hline Reaction temp. $\left({ }^{\circ} \mathrm{C}\right)$ & 140 & 160 & 180 & 200 & 210 \\
\hline Yield $(\%)$ & 65 & 75 & 85 & 78 & 65 \\
\hline Reaction time (h) & 5 & 4 & 3 & 2 & 1 \\
\hline
\end{tabular}

2-Thiazolidinone is synthesized by urea and 2-aminoethylmercaptan hydrochloride and this one-step process proceeds 


\begin{tabular}{lccccc}
\hline \multicolumn{7}{c}{ TABLE-2 } \\
\multicolumn{1}{c}{ EFFECT OF REACTION TIME ON THE YIELD OF THE PRODUCT } \\
\hline \multicolumn{1}{c}{ Reaction time $(\mathrm{min})$} & 120 & 150 & 180 & 210 & 240 \\
\hline Yield $(\%)$ & 60 & 75 & 85 & 70 & 65 \\
Reaction characteristics & Not complete & Not complete & Moderate & Byproducts & Byproducts \\
\hline
\end{tabular}

with high yields, under mild conditions. The structure of the target compound was confirmed by IR, ${ }^{1} \mathrm{H}$ NMR, MS and the purity was $98 \%$ as determined by HPLC. The melting point of the product was $51^{\circ} \mathrm{C}$, which was identical with reported value in the literature ${ }^{8}$. We also optimized the reaction conditions by testing several parameters, such as reaction time (Table-1), reaction temperature (Table-2) and different amounts of raw material (Table-3).

TABLE-3

EFFECT OF THE MOLAR RATIO OF UREA TO 2AMINOETHANETHIOL HYDROCHLORIDE REACTION TEMPERATURE ON THE YIELD OF THE PRODUCT

\begin{tabular}{lllll}
\hline Molar ratio (mol ratio) & 1.0 & 1.2 & 1.5 & 2.0 \\
\hline Yield (\%) & 70 & 75 & 85 & 85 \\
Purity (\%) & 81 & 85 & 98 & 98 \\
\hline
\end{tabular}

With reaction temperature lower than $180^{\circ} \mathrm{C}$, the reaction took place more slowly and a reaction time of 4-5 h, And when the reaction temperature higher than $180^{\circ} \mathrm{C}$, the reaction took place more quickly and a reaction time of 1-2 h, but the yield was also reduced, so moderate reaction temperature was $180{ }^{\circ} \mathrm{C}$.

The reaction proceeded faster, it is found that raw materials were not completed and the yield decreased, on the other side byproducts were formed in long reaction time, so appropriate reaction time was $3 \mathrm{~h}$.

As can be seen from the Table- 3 , the suitable molar ratio of urea to 2-aminoethanethiol hydrochloride is $1.5: 1.0$, the urea amount used reduced 20 compared to the literature ${ }^{9}$.

By experiments utilizing an orthogonal design, optimum synthesis conditions were obtained as follows: the molar ratio of urea to 2-aminoethanethiol hydrochloride is 1.5:1.0, reaction temperature $180 \pm 5^{\circ} \mathrm{C}$, reaction time $3 \mathrm{~h}$. Take the toluene as the extractive solvent, by 2 -aminoethanethiol hydrochloride, yield may reach $85-90 \%$. Through the optimized response condition, the urea amount used reduced to 20 compared to the literature.

\section{Conclusion}

We have successfully reduced the number of steps and 2-thiazolidinone is now accessible in one steps with good yields. we optimized the reaction conditions by testing several parameters, such as extraction solvent, different amounts of raw material, reaction temperature and reaction time, etc. Short steps, high yield and ease of operation of the present approach would permit the hitherto most efficient access to 2-thiazolidinone.

\section{REFERENCES}

1. R. Ottana, R. Maccari, M.L. Barreca, G. Bruno, A. Rotondo, A. Rossi, G. Chiricosta, R. Di Paola, L. Sautebin, S. Cuzzocrea and M.G. Vigorita, Bioorg. Med. Chem., 13, 4243 (2005).

2. P. Vicini, A. Geronikaki, K. Anastasia, M. Incerti and F. Zani, Bioorg. Med. Chem., 14, 3859 (2006).

3. R. Ottana, S. Carotti, R. Maccari, I. Landini, G. Chiricosta, B. Caciagli, M.G. Vigorita and E. Mini, Bioorg. Med. Chem. Lett., 15, 3930 (2005).

4. P.C. Lv, C.F. Zhou, J. Chen, P.G. Liu, K.R. Wang, W.J. Mao, H.Q. Li, Y. Yang, J. Xiong and H.L. Zhu, Bioorg. Med. Chem., 18, 314 (2010).

5. M. Yagisawa, M. Kitano and Y. Morimoto, EP 0387028,1990-09-12.

6. Kawamatsu Yutaka Kogyo K.K., JP 58177983, 1983-10-18.

7. M. Yagisawa, M. Kitano and Y. Morimoto, EP 0387028A2, 1990-0912.

8. J.C. Crawhall and D.F. Elliott, J. Chem. Soc., 3094 (1952).

9. J.G. Michels and G. Gever, J. Chem. Soc., 78, 5349 (1956). 